that support the rights of men who have sex with men and their access to HIV services do exist such as (GALZ) H.O.P/ PSI. Many are routinely punished and shutdown or have their members arrested. UNAIDS reported in 2017 that just one in seven men who have sex with men in Zimbabwe (14.1\%) are aware of their status. International donors such as the Global Fund to Fight AIDS Malaria and Tuberculosis and PEPFAR have attempted to ensure some of their funding is directed towards men who have sex with men. Government restrictions mean this has not materialised.

Disclosure No significant relationships.

\section{P271 A COMMUNITY PERSPECTIVE ON THE IMMEDIATE PRESCRIBING OF ANTIRETROVIRAL THERAPY AT TIME OF A HIV DIAGNOSIS (ARTATD)}

David Crawford*. Positive Life NSW, Surry Hills, Australia

10.1136/sextrans-2019-sti.396

Background The World Health Organisation (WHO) in 2017 published 'Guidelines for Managing Advanced HIV Disease and Rapid Initiation of Antiretroviral Therapy'. Supporting evidence that the prescribing antiretroviral therapy (ART) at the time of an HIV diagnosis (ARTatD) maybe beneficial. Further support arises from the Strategic Timing of Antiretroviral Therapy (START) study and from clinical programs e.g. RAPID Program at San Francisco General Hospital. The START Study shows improved outcomes for all body systems affected by HIV including cardiovascular, lower risk of chronic kidney disease (CKD) and ARTatD may reduce the populating of viral reservoirs within the central nervous system (CNS) at the time of infection.

Methods With an interest in community opinions on ARTatD Positive Life NSW (PLNSW) distributed an online survey using Surveymonkey recording answers from across Australia $(\mathrm{N}=833)$ to 18 questions. Current demographics and HIV status, Attitudes supporting ARTatD if it was recommended, Concerns and problems envisaged on a recommendation of ARTatD, and What would influence their decision on commencing ARTatD

Results Representation from those born in Australia (69\%) and from overseas $(31 \%)$ with an age range 18 to $>75$ years of age of whom identified as 96\% male, $2 \%$ female, 1 nonbinary and $1 \%$ as other and of these $76 \%$ supported ARTatD if it was available. 9\% did not support and 15\% were unsure of ARTatD.

Conclusion Those identifying ARTatD as being the most beneficial identified among their reasons as, if the doctor recommended it, giving a sense of control, protecting sexual partners, protecting the unborn baby for pregnant women. Those not supporting ARTatD identified needing time to adjust, making sure of the diagnosis and prescribed medication was correct. The outcome of this survey will inform how those at the time of a HIV diagnosis will need to be supported if ARTatD becomes a standard recommendation Disclosure No significant relationships.

\section{P272 RESEARCH TO RESOURCE: BOOKLET FOR PEOPLE LIVING WITH HIV ASSOCIATED NEUROCOGNITIVE DISORDER (HAND)}

${ }^{1}$ David Crawford*, ${ }^{2}$ Denise Cummins. 'Positive Life NSW, Surny Hills, Australia; ${ }^{2}$ University of Sydney, Sydney Nursing School, Sydney, Australia

\subsection{6/sextrans-2019-sti.397}

Background Recent estimates of risk for symptomatic HAND range from $18-50 \%$ of those people living with HIV (PLHIV) on combined antiretroviral therapy (cART). Positive Life NSW's (PLNSW) research into the level of knowledge of HAND amongst PLHIV arose from questions raised at a meeting of HIV healthcare and community representatives in early 2015. Questions to be answered: Is there an awareness of HAND? Are PLHIV thinking about and are they concerned about HAND? Have they tried talking to someone about HAND? What was the response to this and the outcome? Did PLHIV want suggestions of how to talk about their concerns to others? The research identified the next steps to develop resources and support programs for PLHIV managing their experiences and concerns living with HAND.

Methods Ethics was granted for a questionnaire to be distributed online via Surveymonkey through PLNSW social media and electronic media platforms. From total responses $(\mathrm{N}=163)$, postcodes of respondents from other states outside NSW $(n=31)$, incomplete responses $(n=6)$ and those from overseas $(n=28)$ were removed, leaving a total of ninety-eight responses from NSW for analysis $(n=98)$.

Results A resource was drafted by healthcare professionals, reviewed by Multicultural HIV and Hepatitis Service (MHAHS) for those with low level literacy, the HIV/AIDS Legal Centre (HALC) covered legalities, and focused tested by PLHIV with HAND before publication. The booklet is now being distributed for use by PLHIV to talk in a meaningful way with healthcare providers and significant others about HAND. The booklet outlines signs and symptoms, seeking further assessment and support, legal assistance and practical advice on living with HAND.

Conclusion PLHIV and service providers alike reading the booklet have applauded the initiative are utilising the resource to speaking with friends and partners and seeking assistance form clinicians.

Disclosure No significant relationships.

\section{P273 UNDERSTANDING THE MENTAL HEALTH ISSUES AND SERVICE NEEDS OF THE TRANSGENDER COMMUNITY IN DELHI, INDIA}

${ }^{1}$ Ramita lyer* ${ }^{2}$ Satyanarayana Ramanaik, ${ }^{2}$ Ravi Prakash, ${ }^{3}$ Purnima Parmar, ${ }^{4}$ Parveen Kumar, ${ }^{4}$ JK Mishra, ${ }^{3}$ Shajy Isac. 'Lee Kuan Yew School of Public Policy, National University of Singapore, Singapore, Singapore; ${ }^{2}$ Karnataka Health Promotion Trust, Bangalore, India; ${ }^{3}$ India Health Action Trust, Delhi, India; ${ }^{4}$ Delhi State AIDS Control Society, Delhi, India

\subsection{6/sextrans-2019-sti.398}

Background Trauma and distress are common characteristics of mental disorder among the Transgender (TG) community. 
However, little is known about the context and forms of mental distress, and the coping mechanisms TGs employ. This study seeks to understand the various mental health issues among TGs in Delhi, and prevalent government service usage patterns. Further, it intends to advocate for the inclusion of mental health services within the existing Government health policies.

Methods Qualitative in-depth interviews were conducted with twenty TGs from Delhi. Purposive sampling was done to maximise variation in relevant socio-demographic characteristics. Respondents were recruited from a targeted intervention programme run by Delhi State AIDS Control Society. An open ended interview guide consisting of a range of mental health themes were used. Interviews were conducted in the local language, Hindi, and transcripts were translated to English. A thematic content analysis was conducted by coding data manually.

Results The study revealed poor mental health among TGs. They face increased societal stigma, discrimination, poverty, familial rejection coupled with extreme physical and social violence, leading to anxiety and depression, with instances of suicidal attempts. Further, to cope with the multitude of problems, alcohol and self-harm are used as temporary escape. Importantly, it is found that the TG community does not avail most government services due to aforementioned causes, which negatively affects their self-esteem and overall mental health.

Conclusion Results of this study reflect heightened mental distress and minimal usage of existing health services among TGs in Delhi. The need of the hour is to improve their mental health through provision of adequate services that are accessible and stigma free. The study proposes that this can be achieved by integrating mental health services within the larger HIV prevention programmes of the Government of India. Disclosure No significant relationships.

\section{P274 LEVERAGING MULTI-LEVEL MONITORING TO ACHIEVE STAKEHOLDER BUY-IN: DESCRIPTIVE LESSONS FROM KEY POPULATION MAPPING IN NIGERIA}

${ }^{1}$ Chukwuebuka Chukwukadibia Ejeckam*, ${ }^{2}$ Kalada Green, ${ }^{3}$ Tosin Adebanjo. ${ }^{1}$ Centre for Global Public Health, University of Manitoba (Nigeria Country Office), Program, Federal Capital Territory, Nigeria; ${ }^{2}$ Centre for Global Public Health, University of Manitoba, Programs, Abuja, Nigeria; ${ }^{3}$ National Agency for the Control of AIDS, Strategic Knowledge Management, Abuja, Nigeria

\subsection{6/sextrans-2019-sti.399}

Background Effective processes produce quality outcomes. For key populations (KPs) intervention, quality data that enjoys the buy-in and ownership of community members and other stakeholders is critical for optimal program outcome. In Nigeria, some previous efforts at mapping KPs have not enjoyed the full buy-in of key stakeholders with the credibility of study data and associated findings being challenged by stakeholders, especially the KP community. This situation adversely affected HIV epidemic management in the country. A multi-layer monitoring system was initiated across national and sub-national field operations in order to ensure protocol compliance, quality data, community ownership and general stakeholder buy-in.

Methods A national technical team (NTT) was constituted comprising of representatives from all critical actors, especially from the key population community with a mandate to ensure efficient study delivery. At the sub-national level, a similar body was put in place across all the 10 study states. The lead technical partner, the University of Manitoba, and the study administrator, the Society for Family Health, also had monitors and study coordinators who were deployed to coordinate and monitor the field operations across all 10 study states. The National Agency for the Control of AIDs (NACA) acting as the principal investigator provided leadership and guidance. Programmatic mapping approach involved a 2-step hotspot listing and validation phases known as Level 1 and Level 2. At both phases, stakeholders were involved in routine field monitoring activities.

Results Sub-national level report disseminations were conducted across all the participating study states with all stakeholders, including representatives from the 3 nationally recognized KP groups - FSW, MSM \& PWIDs, accepting that the data reflected findings at the spots.

Conclusion It is imperative to involve critical stakeholders from planning to monitoring of study processes as it engenders community ownership- a positive leverage for the efficient delivery of community impact interventions for KPs. Disclosure No significant relationships.

\section{P275 TOWARDS THE MANAGEMENT OF HIVIAIDS PATIENTS IN PENTECOSTAL CHURCHES IN UGANDA: A CASE OF EDEN AND BETHEL CHURCHES IN KAMPALA}

Rebecca Nantalo Namige*. Gomba Community Health Society, Community Organisation, Kampala, Uganda

\subsection{6/sextrans-2019-sti.400}

Background Main stream churches in Uganda have been known to be at the fore front of extending medical services, particularly in the areas of HIV/AIDS. However, Pentecostal churches seem not to be following suit, given their belief in miraculously healing by God. The aim of this study was to; Investigate the occurrence and management of HIV/AIDS miraculous healing in the PentecostalsChurches. - Identify the challenges faced in quantifying AIDS/HIV miraculous healings in Pentecostal Churches. - Make suggestions for the best practices on AIDS/HIV management alongside the belief in miraculous healing. - Find out if there is complete healing of HIV/ AIDS among believers

Methods Questionnaires, interviews and observation were used as instruments for data collection. Church leaders werepurposively sampled and convenience sampling among believers. It wasdiscovered that believers knew about HIV \& medical interventions towards its management but needed better communication channels/models to bridge the awareness gap \&change of attitude towards HIV miraculous healing to strengthenHIV patient management in Pentecostal churches.

Results The study showed that the application ofmedical based HIV prevention in Pentecostal churches was bedevilled by poor models of communication applied, lack of specific programs, inadequate finances, limited HIVawareness church based trainings, above of all the strong miraculous healing beliefs.

Conclusion It was recommended, that the application of approximate communication models be developed;Church leaders develop HIV preventionprograms in line with government policy; Churches engage Government and funderfor funding; and a creation of aliaison platform between Pentecostal and main stream churches for HIV program awareness. 